\title{
NUEVOS ALUMNOS, NUEVOS RETOS Y RECURSOS DIFERENTES: UN LIBRO DIGITAL PARA LA ENSEÑANZA DE LA HISTORIA ANTIGUA
}

\author{
New Students, New challenges and Different Resources: \\ A Digital Book for the Teaching of Ancient History
}

\author{
Víctor Sánchez Domínguez \\ vsanchez1@us.es \\ Escuela Universitaria de Osuna. España \\ Alfonso Álvarez-Ossorio Rivas \\ alfossorio@us.es \\ Universidad de Sevilla. España \\ Fernando Lozano Gómez \\ fernandolozanogomez@yahoo.com \\ Universidad de Sevilla. España
}

Fecha de recepción: 01/03/2019

Fecha de aceptación: 30/05/2019

Resumen: Esta aportación presenta los resultados de los proyectos de Innovación docente gestionados por miembros del Dpto. de H. a Antigua en 2011 y 2017 para generar nuevas dinámicas de aprendizaje en nuestras materias y cambiar los materiales que utilizamos en las mismas a fin de modernizarlos y adecuarlos a las nuevas necesidades del alumnado. El primero de los proyectos realizó una labor de investigación para identificar las necesidades a nivel de contenidos del alumnado de la asignatura de Fundamentos de Historia en el grado de Educación Primaria, mientras que el segundo se centró en crear un nuevo modelo de manual universitario adecuado a las necesidades tanto de este alumnado como el de otros grados en los que el Dpto. imparte clases.

Los objetivos que nos marcamos fueron identificar las características del alumnado y su grado de conocimientos, valorar el proceso de aprendizaje, identificar las principales dificultades que tienen frente a los contenidos de nuestras materias, diseñar unos nuevos materiales que las solucionaran y valorar el grado de éxito de los mismos. Para ello diseñamos un cuestionario que se pasó a todos los grupos que cursan la asignatura, teniendo la suerte de tener una muestra significativa de entre 
quinientos a seiscientos alumnos y durante varios años procuramos diseñar los nuevos materiales que vieron la luz en forma de libro electrónico maquetado y publicado gracias al proyecto de Innovación docente de 2016/17/ y que comenzó a usarse en el cuso 2016/17, presentando un aumento en el índice de aprobados y permitiéndonos reflexionar sobre la necesidad de continuar el proceso de reforma de contenidos, materiales y metodologías para estas asignaturas.

Palabras clave: Historia Antigua; Ciencias Sociales; Materiales didácticos; Historia de España.

Abstract: This contribution presents the results of the teaching Innovation projects managed by members of the Ancient History department in 2011 and 2017 to generate new learning dynamics of our subjects and change the materials we use in them in order to modernize them and adapt them to the new needs of the students. The first of the projects carried out a research work in order to identify the needs at the content level of the students of the Fundamentals of History subject in the Primary Education degree. The second focused on creating a new model of university manual appropriate to the Needs of these students as well as other grades in which the Department teaches.

The objectives we set ourselves were to identify the characteristics of the students and their level of knowledge, assess the learning process, identify the main difficulties they face in the content of our subjects, design new materials to solve them and assess the degree of success thereof. For this, we designed a questionnaire that was passed to all the groups that take the course, having the luck to have a significant sample of between five hundred and six hundred students and for several years, we tried to design the new materials that came out in the form of an e-book. and published thanks to the teaching innovation project of 2016/17 and that began to be used in the 2016/17 period, presenting an increase in the pass rate and allowing us to reflect on the need to continue the process of content, material and methodologies for these subjects.

Keywords: Ancient History; social sciences; educational materials; Spanish History.

SUMARIO: 1. Introducción. 2. El problema de la enseñanza de la Historia en nuestros días. 3. Un nuevo alumnado, un nuevo reto: "Fundamentos de Historia: Historia de España» (2011-2012). 4. El libro digital. 5. Resultados de la aplicación. 6. Conclusiones preliminares, camino a un libro 3.0. 7. Anexo I Imágenes. 8. Anexo II - Encuesta Proyecto. 9. Referencias bibliográficas.

\section{INTRODUCCIÓN}

Como hemos denunciado en alguna otra ocasión, la última reforma educativa, en su proceso de búsqueda de la calidad, ha decidido priorizar algunas áreas de conocimiento en favor de otras, primar la adquisición de ciertas competencias con el fin de adecuar la formación de nuestro alumnado a un mundo y más concretamente a un mercado cambiante, con nuevas necesidades (Sánchez, Álvarez-Ossorio, Alarcón y Lozano, 2018). Esta estrategia ha hecho perder a las humanidades, por un lado, visibilidad en el currículum y, por otro, calidad en sus contenidos. Si analizamos la LOMCE, por ejemplo, podemos observar cómo los nuevos programas educativos, en sus diferentes etapas, abordan las ciencias sociales en general, y la historia en particular, de manera superficial. Si bien estos programas hacen referencias a nuevos sistemas de aprendizajes, los planteamientos que observamos en objetivos y contenidos mantienen el carácter memorístico en nuestras disciplinas, como denuncia López Facal para las enseñanzas medias (2014, pp. 279-80), 
reorientándolas en el mejor de los casos hacia lo anecdótico, intentando crear un aprendizaje teóricamente más significativo con unas sugerencias metodológicas de carácter superficial, sin profundizar en cómo se aplican dichas soluciones ni preocuparse por la formación que han de tener los docentes que opten por alterar los modelos tradicionales de clases a fin de aplicar estos principios teóricos de la reforma.

Además del problema en la formación del alumnado, se observa también cómo la adaptación en los niveles más básicos del currículum ha provocado un deterioro en la cultura general de la población, hecho agravado en lo referente a la Historia Antigua. Es en esta realidad donde se constata la pérdida de conocimientos que hace décadas se consideraban generales y nos plantea un nuevo reto en la etapa universitaria, ya que debemos afrontar la formación de unos estudiantes con poca base en un momento en que los especialistas en didáctica aconsejan partir siempre de los propios conocimientos del alumnado y fomentar que ellos construyan su conocimiento. Este problema se agrava aún más debido a que las carencias que nuestro alumnado presenta no quedan circunscritas a los meros contenidos de nuestras áreas, si no que en muchos casos atañen también a su grado de independencia y autonomía en el proceso de aprendizaje, una dificultad que nos aleja de él y que obliga al docente a reorientar el proceso de enseñanza a fin de desarrollar estas competencias. Nos encontramos pues en una tesitura en la que, si seguimos el símil constructivista, el alumno universitario, formado desde su más tierna infancia en este proceso de enseñanza-aprendizaje, debiera ser el equivalente a un técnico con nociones arquitectónicas básicas y acceso a unos materiales de calidad media para elaborar por él mismo y bajo nuestra orientación la construcción de su propio proyecto de conocimiento superior universitario; sin embargo al docente le da la impresión de que el alumnado, lejos de estar a ese nivel, se asemeja más a un peón nuevo en la empresa, con nociones básicas de construcción, que busca a su oficial para que le diga dónde están los materiales, le interprete los planos y le de las instrucciones para levantar los muros. Esta percepción, puramente subjetiva y que no es generalizada, nos llevó a plantearnos qué nivel de conocimientos tenían nuestros alumnos y en caso de ser insuficiente cómo podríamos mejorar el proceso de aprendizaje abordando tanto elementos básicos del currículum como la metodología docente, la presentación y accesibilidad de los contenidos, así como la adecuación de los mismos al nivel del alumnado.

El presente trabajo es el producto parcial de una serie de proyectos de innovación docente coordinados por los profesores del Dpto. De Historia Antigua de la Universidad de Sevilla, quienes aún hoy continuamos abordado esta problemática. En este trabajo se presentan los resultados de modificación de materiales y adecuación de los contenidos en un proceso gestionado en dos fases, desarrolladas mediante los proyectos de innovación docente de 2011/12 y 2016/17 centrados ambos en la asignatura Fundamentos de Historia en el grado de Educación Primaria. El primero de los proyectos se dedicó a realizar una investigación educativa, 
cuyo objetivo principal era identificar las características del alumnado y la profundidad de sus conocimientos en historia, a fin de tener una visión general del punto de partida que debíamos abordar en nuestra materia. El segundo, buscó como objetivo principal el diseño de nuevos materiales didácticos que acortaran el abismo entre los conocimientos iniciales del alumnado y los que se marcan en los objetivos de nuestras asignaturas, consolidando los conocimientos que el alumno tiene y proporcionándoles nuevas herramientas con que ampliarlos, tanto para la asignatura que ha servido como objeto de estudio, como para con otras propias del área, abordando conjuntamente un cambio en los modelos metodológicos a nivel de desarrollo de las clases y evaluación en la educación superior.

\section{EL PROBLEMA DE LA ENSEÑANZA DE LA HISTORIA EN NUESTROS DÍAS}

Cicerón definió la historia como magistra vitae (Cic. Orat. II. 36) y desde siempre la concepción del pasado y la memoria han sido una parte fundamental de las sociedades. Es imposible encontrar un diseño curricular desde los programas más tempranos que no preste atención a la historia y su papel como formadora. Actualmente esta se encuentra presente en las diferentes etapas educativas y las problemáticas derivadas de su proceso de enseñanza-aprendizaje han sido estudiadas desde diferentes ámbitos de las Ciencias Sociales. Estudios como los de Cooper (2002) abordan la necesidad y problemas que tiene el niño desde las etapas más tempranas en relación con la percepción del devenir histórico, su comprensión sobre el concepto cambio, las nociones de tiempo, espacio y causalidad, así como su análisis ${ }^{1}$; unos problemas que en algunos casos se perpetúan durante las etapas educativas posteriores.

Por otro lado, no hemos de negar en este estudio la influencia de Caballero Oliver (2002) y su aportación sobre las dificultades que el alumno de secundaria presenta en este proceso de aprendizaje dándonos un claro listado que a continuación exponemos:

1. La existencia de ideas previas, provenientes de etapas anteriores y de su entorno social (o incluso creadas por él mismo y su experiencia personal).

2. El rechazo a la historia y a las cuestiones de carácter social que estén asociadas a ella debido a su lejanía y falta de practicidad en su vida cotidiana.

3. La tendencia a realizar juicios morales de los hechos históricos.

1 Estos problemas analizados por Cooper en sus primeros capítulos de su obra sobre didáctica de la Historia en Educación Infantil y Primaria (2002) son analizados en profundidad por muchos otros autores especialistas en didáctica como Trepat y Comes (1998), Hernández Cardona (2002), entendiéndose como una realidad a tener en cuenta por el docente en el proceso de enseñanza-aprendizaje. 
4. La tendencia a simplificar los hechos históricos para comprenderlos mejor.

5. El mezclarlos con sus experiencias personales generando modelos de desarrollo basados en esta misma.

6. Los problemas que la mente del alumno tiene con la comprensión del tiempo histórico debido a su abstracción.

7. Por último, las dificultades de los alumnos en interpretar documentos propios de la materia como mapas, tablas, gráficas y cronogramas, debido de nuevo a la necesidad de abstracción que estas actividades requieren.

Si bien problemas como la tendencia a los juicios morales y la comprensión del tiempo histórico debieran haberse subsanado, o al menos mitigado, en la etapa primaria, nos encontramos que el profesorado de educación secundaria advierte la continuidad de ese peso que dificulta el aprendizaje de la historia, hecho que para nuestra sorpresa se sigue identificando en el alumnado de educación superior. La subjetividad, la falta de capacidad imaginativa y abstractiva del alumno se une con una visión crítica hacia la historia derivada del fracaso de un aprendizaje tradicional poco significativo en que la historia queda relegada a un mero relato que debe ser memorizado por el alumnado y transmitido en las pruebas parciales realizadas durante el curso y en el acceso a los estudios superiores.

Este planteamiento memorístico, que podría rastrearse en la tradición docente de los niveles de primaria y secundaria, no fue un problema en la educación universitaria hasta hace relativamente poco tiempo. Sin embargo, el contexto educativo ha ido variando con el cambio de nuestro presente y esta nueva realidad, distinta a nivel social, económico y cultural. En esta situación se ha desmontado el escenario en el que veníamos desarrollando nuestra actividad docente sustituyéndolo por uno muy diferente, donde el alumnado ha dejado de ser público y se le ha obligado a subir a escena sin explicársele muy bien el cómo ni el porqué. Hoy en día necesitamos otro tipo de alumnos, otro tipo de aprendizaje y otro tipo de profesorado. Esta realidad se ha convertido en un mantra que, desde las administraciones educativas, se repite una y otra vez sin ser explicado a los viejos y nuevos actores que conviven en el escenario educativo.

Desde el punto de vista del docente, los cambios se han ido sucediendo por medio de acciones de formación y nuevos requisitos como la creación del título del MAES (Master de profesorado en Secundaria, BACH y FP) que amplía la formación que venía impartiéndose con los cursos de aptitud de profesorado, el tradicional CAP. En la universidad se vienen desarrollando cursos de formación específicos como los impartidos en Sevilla de la FIDOP, en los que desde la coordinación se aborda la mejora del docente a diferentes niveles didácticos (Porlan, 2017), además de los cursos de formación permanente, donde están cada vez más presentes nuevas metodologías, nuevos recursos o incluso adaptaciones docentes de algunos no tan nuevos pero necesarios como la retórica. 
Esta nueva corriente formativa, que busca concienciar al profesorado y prepararlo para el nuevo reto docente, tiene en muchos casos su plasmación en los proyectos de Innovación docente como los que en este trabajo presentamos en los que investigamos cómo cambiar nuestro magisterio para actualizarnos y alcanzar a un alumnado cada vez más distante.

\section{UN NUEVO ALUMNADO, UN NUEVO RETO: "FUNDAMENTOS DE HISTORIA: HISTORIA DE ESPAÑA" (2011-2012)}

El alumnado y su relación con los contenidos son los principales objetivos de los proyectos cuyos resultados aquí se presentan. Tras realizar una rápida valoración sobre el alumnado matriculado en la asignatura de Fundamentos de Historia: Historia de España, asignatura que viene impartiéndose desde el curso $2010 / 11$ en la Universidad de Sevilla por los departamentos de H. a Antigua e H.a Contemporánea, los docentes de la materia percibieron una serie de problemáticas especiales.

En primer lugar, debíamos de tener en cuenta las características del alumnado del siglo XXI, un alumnado que en 2010 se había criado en la era digital y que hoy en día ya podemos decir que es nativo digital, mientras que el profesorado y los diseñadores de los programas no lo somos. Su realidad pertenece a un mundo diferente, conectada a las grandes redes de información las cuales son, hoy en día, un factor determinante y activo que bombardea al estudiante con los contenidos que el mercado genera, en una compleja relación de oferta-demanda en la que la sociedad es sujeto paciente de ambas, ya que las dos son creadas por y para que ella consuma. El alumnado puede que llegue a nosotros habiendo pasado más de la mitad de su vida, tal vez casi toda ella, usando soportes digitales y mirando a través de ellos por una ventana que les ha presentado un mundo multimedia lleno de color, acción, emoción, todo de manera instantánea y conseguido sin ningún esfuerzo. Frente a ello, nuestros programas, entregados hasta hace unos años en papel fotocopiado, les ofrecen un listado de contenidos ajenos a su experiencia, reforzados por una bibliografía para ellos desconocida y que no saben ubicar, a veces ni físicamente, en la realidad.

En segundo lugar, además de las particularidades tecnológicas del alumnado en general encontramos que los estudiantes del grado en Educación Primaria eran y son a su vez diferentes al alumnado que nosotros acostumbramos a tratar en otras titulaciones. Nuestra enseñanza superior ha sido tradicionalmente ofertada a alumnos de licenciatura de Historia, Historia del Arte, Geografía y en algunos títulos del área de Humanidades, hoy todos grados universitarios. Existe una gran diferencia, pues los estudiantes del grado de educación primaria no adquieren los mismos conocimientos sobre los procesos históricos, tanto 
en la Península Ibérica como en otros ámbitos geográficos. Los conocimientos históricos de los estudiantes de los grados en Educación Primaria se limitan en muchas universidades a los adquiridos durante sus etapas formativas previas a los estudios de grado, y en el caso de la Universidad de Sevilla, a la docencia que tiene asignada el Departamento de Historia Antigua y que comparte con el de Historia Contemporánea, en segundo curso del título en la asignatura de Fundamentos de Historia.

Nos encontramos, por tanto, con la problemática de que cuando estos alumnos estudiaron los períodos históricos que iban a ser tratados en nuestra parte de la asignatura, tenían apenas doce o trece años. Por lo tanto, el nivel de conocimientos alcanzados distaría, al menos teóricamente, de lo que habría que exigirles durante las clases de una asignatura universitaria.

Pero es que, además, el alumnado que toma parte de esta asignatura presenta esa característica adicional ya mencionada que debe ser tenida en cuenta a la hora de diseñar la estrategia docente de la misma (solo reciben una única materia de Historia) y esta tiene como objetivo principal formarles de cara a una eventual experiencia profesional que se centraría en el campo de la Educación Primaria, con un alumnado al que tendrían que transmitirle solo una parte reducida de los conocimientos que pudiesen adquirir a lo largo de este curso. Esto conforma un tercer problema, ya que el estudiante entiende que los conocimientos que debe tener en historia deben ser los justos para asimilarse a los aprendidos en la etapa primaria, una opinión que choca con los planteamientos de la asignatura.

Además de esto surge un último problema metodológico, ya que la clase en historia suele tener una metodología tradicional centrada en un modelo expositivo con un, cada vez mayor, grado de participación del alumnado que debe preparar de forma autónoma los materiales de la asignatura a través de fuentes de diferente tipo y rango, pasando por fuentes literarias primarias, fuentes materiales, mapas, etc. Esta metodología docente necesita de unas ideas previas y de un trabajo diario a partir de la aplicación de unas destrezas que no son tan comunes en nuestro alumnado y en su día a día a la vez que generan un sistema de evaluación de los contenidos al que tampoco están acostumbrados.

Para encontrar una solución clara a estos problemas de metodología y contenidos desde el Dpto. de H. a Antigua determinamos que lo primero que necesitábamos hacer de manera imprescindible era un estudio previo que nos indicase el nivel de conocimientos básicos de Historia de España Antigua y Medieval de los alumnos que llegaban a nuestras clases. El objetivo era doble, puesto que, además de determinar cuál podía ser el tipo de alumnado que nos íbamos a encontrar, en lo referente a dominio de los rudimentos de la materia, podíamos conocer las carencias de ese alumnado en la misma e implementar las medidas necesarias destinadas a subsanarlas durante el desarrollo de nuestras clases y en nuestra nueva herramienta de trabajo. 
Este proyecto, resultó sumamente interesante y útil para los docentes del área, ya que por medio de un sistema de encuestas identificamos las ideas previas del alumnado. Estos cuestionarios confirmaron nuestras sospechas sobre el nivel de conocimiento de los periodos históricos que teníamos que explicar. Así mismo, nos permitieron averiguar qué temas eran más cercanos y cuáles eran más ajenos a su formación.

Así pues, por medio del primer proyecto de investigación docente, dirigido por el prof. Álvarez-Ossorio, nos propusimos identificar de manera real los problemas a subsanar. Para ello, realizamos un cuestionario con una batería de treinta preguntas tipo test con tres posibles opciones de respuesta de la que solo una era correcta. Para la elaboración de las mismas usamos bibliografía correspondiente a manuales y libros de texto de enseñanza secundaria y bachillerato, a fin de trabajar con materiales que nuestros alumnos ya conociesen y generamos diferentes tipos de preguntas con diferentes grados de complejidad (véase anexo II).

La encuesta fue realizada por trescientos sesenta y cuatro alumnos (364), sobre un total de 569 matriculados, entre febrero y abril de 2012 durante el curso 2011/12, segundo año de vigencia del Grado, cuya primera promoción arrancó en el curso 2010/2011. La primera conclusión que obtuvimos de las encuestas fue que existe un elevadísimo grado de absentismo entre el alumnado. Creemos que el hecho de que la encuesta se realizara el primer día de clase de cada grupo incidió en esta cuestión, ya que en nuestra experiencia el alumnado se va incorporando paulatinamente al curso y además contamos con un porcentaje no presencial variable debido a cuestiones laborales o derivadas de ya haber cursado la asignatura. Esto nos obliga, en parte por no existir estadísticas de asistencia en otros momentos del curso que permitieran esclarecer esta situación, a solo contar con los datos de la asistencia de un $63 \%$ de media.

En un análisis de las preguntas, debemos decir que están en la línea de lo que esperábamos. Estos son los valores numéricos y porcentuales presentados en 2017 en el congreso INNTED (Sánchez, Álvarez-Osorio, Alarcón y Lozano, 2018, pp. 169-180).

\begin{tabular}{cccc} 
Número de aciertos & Alumnos & Porcentajes & Número de aciertos \\
\hline $0-5$ & 0 & $0 \%$ & $0-5$ \\
$5-10$ & 47 & $12,91 \%$ & $5-10$ \\
$11-14$ & 144 & $39,53 \%$ & $11-14$ \\
$15-20$ & 162 & $44,57 \%$ & $15-20$ \\
$21-30$ & 11 & $3,02 \%$ & $21-30$ \\
\hline
\end{tabular}

Tabla 1. Valores numéricos y porcentuales de las encuestas. Elaboración propia. 


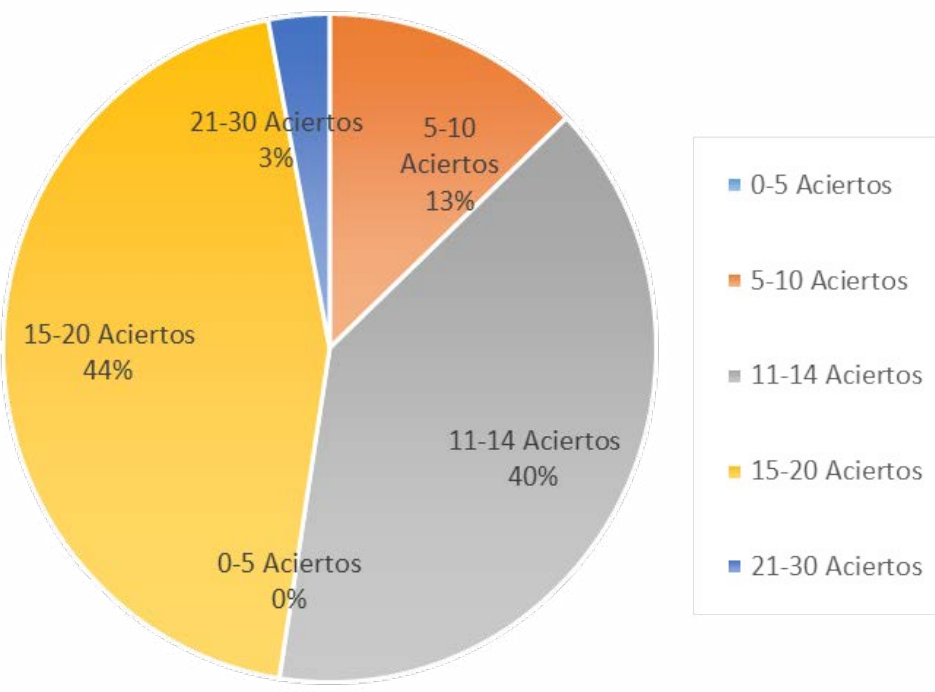

Gráfico. Resultados de las encuestas de manera porcentual. Elaboración propia.

Tras revisarlos de manera pormenorizada, el segundo dato de interés, tras denunciar el grado de absentismo, es que solo un $13 \%$ tiene un nivel de conocimientos previos que podríamos considerar ínfimo con un promedio de aciertos inferior a 10 preguntas de 30; sin embargo sí nos percatamos de que el porcentaje de alumnos que no alcanzaban un nivel mínimo para afrontar una asignatura era alarmante, puesto que si sumamos la cifra anterior a la de los alumnos de la horquilla entre once y catorce aciertos (un 39,53 \%) la cifra superaba el $50 \%$. Por otro lado, un dato esperanzador es que, pese a todo, existía un $44 \%$ de alumnos que tenían unas nociones básicas de la Historia de España, hecho que nos permitía ser optimistas de cara al desarrollo de la asignatura. Por último, creemos que destaca sobremanera el escasísimo número de alumnos que alcanzan un nivel que podríamos considerar óptimo antes de iniciar el curso. Son solo once los estudiantes que superan la veintena de aciertos, con el agravante añadido de que solo uno fue capaz de responder a más de veinticinco preguntas de forma correcta (veintiocho aciertos) y que no hubo ninguna encuesta con todas las respuestas correctas.

\section{EL LIBRO DIGITAL}

Una vez finalizada esta fase de recolección de datos se procedió, como adelantábamos en la introducción, a diseñar una metodología docente destinada a solventar las carencias que se observaron entre el alumnado a fin de dotarles de los elementos fundamentales para el conocimiento de la Historia de España y orientarles en cómo debiera ser la preparación de sus clases en el momento en 
el que se dedicasen profesionalmente a enseñar historia de España a alumnos de Primaria. Durante el tiempo transcurrido entre ambos proyectos se buscaron diferentes medidas para conseguir este fin. Se elaboró una bibliografía general con los principales manuales de cada tema, siendo entre otros, la obra de Mitre sobre la España Medieval (1979), la de Suárez Fernández (1986), el manual de Historia de España de García de Cortazar (2009), la monografía dirigida por Alvar Ezquerra sobre la Historia Antigua de España (2008), o la monografía de Barceló y Ferrer sobre la Hispania romana (2007). Esta bibliografía era la básica que se les exigía a los alumnos de primer curso en la licenciatura de Historia, después grado. Otra de las medidas fue la elaboración de materiales en red por parte de uno de los componentes de estos proyectos, el prof. Sánchez Domínguez, junto con el prof. Somé Laserna, producto de una convocatoria de la universidad de Sevilla y que derivó en la adaptación de parte de esos materiales on-line en un PDF de Historia Antigua y Medieval que los alumnos convirtieron en su libro de apuntes particular.

Debido a los datos extraídos del proyecto de investigación y a los resultados de estas medidas particulares se pensó en crear un nuevo proyecto para ampliar los objetivos y plantearse como tarea principal el desarrollo de una herramienta nueva, de gran alcance y bajo coste que permitiera trabajar los contenidos fundamentales, no ya para el grado de Educación Primaria, sino para los primeros cursos de las licenciaturas de ciencias sociales en donde contenidos sobre la Historia Antigua y Medieval de la península están presentes.

A partir de ese momento comenzó el diseño de un nuevo proyecto centrado en la elaboración de lo que se ha denominado manual 2.0. La idea era crear un libro de texto en formato digital que se presentaba con unos objetivos claros y que se encontraba amparado y vinculado a un nuevo proyecto de innovación docente (2016/17). En primer lugar, perfilamos los nuevos objetivos que se recogen en la memoria del mismo:

1. - Consensuar y armonizar los contenidos de las asignaturas dedicadas al estudio del Mundo Clásico en los primeros cursos de los Grados en Historia y Educación Primaria.

Entendíamos que el manual no podía circunscribirse solo al plan de estudios para el que comenzamos el proyecto, ya que algunas de las características de los alumnos (necesidad de motivación, de impacto visual y dinamismo de los contenidos), al igual que los contenidos, eran comunes a otras materias de diferentes grados, por lo que nos propusimos dar una visión más general y completa a los temas, adaptándolos a asignaturas como «Historia de la Península ibérica en la Antigüedad», "Historia del mundo clásico», "Roma e Hispania», o "Historia de España en la Edad Media», "Historia de Al-Andalus», pertenecientes a los grados de Historia y al doble grado en Geografía, Gestión del territorio e Historia. 
2. Establecer un debate sobre los contenidos fundamentales, los puntos claves, las informaciones más relevantes y las metodologías más exitosas para la enseñanza entre los profesores del Departamento de Historia Antigua que imparten docencia en los grados y las asignaturas implicados en el proyecto, así como con el profesor que tiene a su cargo estos contenidos en la Escuela Universitaria de Osuna.

Conseguir este objetivo era algo fundamental, ya que se buscó en todo momento generar un debate entre editores y autores para adaptar los contenidos partiendo de las experiencias de los docentes en el periodo de implantación del nuevo sistema de grados universitarios. Esta metodología de trabajo se basaba en el análisis, la reflexión y la autocrítica derivada de los resultados académicos, así como de los análisis realizados por medio de las encuestas creadas en el proyecto de innovación docente de 2012 que eran actualizados cada año.

3. - Generar unos materiales docentes que superen las características de los manuales tradicionales de Historia Antigua que resultan para el alumnado del Grado de Educación Primaria excesivamente teóricos, con demasiado texto y poca atención a la parte práctica de la docencia.

Para que este objetivo se materializara era necesario idear un nuevo formato que renovara los manuales tradicionales en una versión mucho más visual, con más recursos didácticos, que prestara además atención a la faceta práctica necesaria para los futuros docentes.

4. - Desarrollar un nuevo método de prácticas en el ámbito del conocimiento del Mundo Antiguo que genere asimismo una metodología alternativa de evaluación de los alumnos.

5. Permitir a los alumnos ejercitar habilidades fundamentales para el ulterior desarrollo de su vida académica y profesional, tales como las relativas a la oratoria (capacidad de expresarse en público y de transmitir de forma clara y directa conocimientos e ideas), al trabajo en equipo y al manejo de nuevas tecnologías, fomentando siempre una atmósfera de pluralidad y tolerancia.

6. - Permitir adquirir al alumno una visión global de la actividad docente, siendo fundamental el que fuera consciente de su responsabilidad en la toma de decisiones y en el diseño de las pautas de trabajo a seguir.

Uno de los problemas era el derivado de la evaluación de la asignatura, el cual supuso un reto, ya que el alumnado no estaba acostumbrado a la elaboración de respuestas extensas y razonadas que se exigían de manera tradicional en las asignaturas de la licenciatura. Además, la asignatura en el Grado de Primaria estaba orientada hacia la docencia y era necesario un sistema que desarrollara sus capacidades docentes, por lo que fue imprescindible la elaboración de un nuevo sistema que debía plasmarse en el futuro manual. Así pues, estos objetivos abordaban estos puntos clave que resaltábamos en los proyectos de innovación docente, pues se centraban en la elaboración de un sistema de prácticas en las que se unieran el 
interés del profesorado para que los alumnos profundizaran en los contenidos del temario junto a la posibilidad de que el propio material se convirtiera en una herramienta útil para el alumnado cuando se convirtiera en profesorado de primaria. Por este motivo, se diseñó un sistema de prácticas que partía de la elaboración de materiales asimilables a las tradicionales unidades didácticas, pero con características propias, destacando: una menor duración, la adaptabilidad al temario propio de la Educación Primaria a fin de ser usadas de manera complementarias, el trabajo de temas históricos con poca visibilidad en el currículum y la preocupación por temas transversales como la coeducación, la divulgación del patrimonio local, el papel de las mujeres, etc. Estas "UDs» eran trabajadas y diseñadas de manera grupal y se exponían con posterioridad en clase, aunando un trabajo de investigación histórica con uno de diseño didáctico.

7.o Fomentar el desarrollo de la capacidad crítica y la creatividad entre el alumnado.

Por último, nos planteamos que era fundamental para cualquier estudiante de historia el desarrollar el espíritu crítico que le permita entender los hechos históricos y analizarlos reduciendo el grado de influencia de elementos externos como son las diferentes opiniones y tendencias historiográficas. Por esta razón, era necesario que el nuevo manual presentara diferentes visiones y se apoyara en fuentes primarias contrapuestas para que el alumno accediera al conocimiento histórico de la manera más directa posible.

Tras definir objetivos aprovechamos la experiencia de varios de los miembros del equipo para comenzar a diseñar el formato, así incorporamos elementos de la revista National Geographic, para la que el profesor Lozano había trabajado (Lozano Gómez, 2013), la experiencia divulgativa del profesor Ávarez-Ossorio en su obra sobre la historia de Bollullos de la Mitación junto a F. A. Rivas Rivas (2006), así como nuestros conocimientos sobre las revistas de divulgación históricas más exitosas en el ámbito nacional en los últimos años, como Iberia Vieja, Desperta Ferro, La aventura de la Historia, etc. Las cuales estudiamos tanto en su composición, como en el tipo de información que incorporaban, el formato e incluso su difusión.

Título de la revista

Ejemplares vendidos en 2014

\begin{tabular}{cc}
\hline National Geographic & 138389 \\
Muy Historia & 93050 \\
La aventura de la Historia & 52900 \\
Historia y Vida & 58147 \\
Historia de Iberia vieja & 26750 \\
\hline
\end{tabular}

Tabla 2. Datos sobre las tiradas de las principales revistas de divulgación histórica, rescatado de <http://historicaldigest.blogspot.com.es/2014/06/el-boom-de-las-revistas-de-historia.htm/>. Consultado 30/06/2017. 
El incorporar estos elementos de diseño editorial tan poco ortodoxos en los manuales generales universitarios vino respaldado por la semejanza que en ellos percibíamos en algunos aspectos del diseño con los libros de las asignaturas de Ciencias Sociales de educación primaria, que ya los alumnos habían trabajado en otras asignaturas especializadas en didáctica y que en su futura carrera profesional utilizarían como herramientas propias. El acceso a libros de texto nos permitió entrelazar los elementos de las revistas de éxito editorial con las estructuras de esos manuales, dotándolos de los contenidos adecuados para alumnos universitarios. Si bien es cierto que hoy en día hemos conocidos nuevos formatos de libros multimedia como por ejemplo el «edubook» de Vicen Vives (<http://edubook.vicensvives. com/es>) o «somos link» de la editorial Edelvives (https://www.somoslink.com/ presentacion/>) y así muchos otros, en el momento de la edición del libro y en el ámbito universitario existía y existe una carencia en el aspecto de diseños editoriales adaptados al nuevo alumnado, por lo que el planteamiento de generar un nuevo modelo de manual en formato digital y con nuevos elementos resultó un proyecto atractivo e innovador que buscaba renovar herramientas y contenidos para las materias arriba citadas.

Una vez aclarado el modelo de libro que queríamos y que teníamos capacidad de hacer, el trabajo de coordinación y selección quedó en manos de los coordinadores de la obra, quienes buscamos entre el profesorado de la asignatura la experiencia y formación necesaria para diseñar por medio del sistema de cuadros y dosieres propio de las revistas consultadas cada uno de los siete capítulos de que consta el libro. Así mismo, se contactó además con especialistas externos de otros departamentos para completar los contenidos más alejados a nuestra especialidad, especialmente los temas de la Historia Medieval.

Por medio de varias reuniones se crearon unos criterios generales conforme a los contenidos que se tenían que tratar, la extensión de los mismos, los materiales que se debían diseñar y el formato que deberían tener. En paralelo, y apoyándonos en la iniciativa del Dpto. de Historia Antigua de generar una base de datos de imágenes libres de derechos para elaboraciones propias de materiales docentes, se trabajó para que parte de esos materiales fueran a parar al equipo de diseño y maquetación bajo la dirección de María Luisa Rodríguez Jiménez, titulada en artes gráficas.

De esta manera se estableció que los capítulos debieran componerse de apartados en número de entre 6 a 8. Cada apartado abordaría los contenidos generales e incorporaría estudios específicos sobre aspectos destacados de cada tema que podrían ser recogidos por cuadros de en torno a 500 caracteres o dossieres de unos 3000 caracteres, según la extensión necesaria (ver imagen 9, 10 y 11). Se estableció que todos los capítulos llevaran incorporadas unas líneas del tiempo al inicio de los mismos, a fin de facilitar la localización temporal del alumnado, hecho que no siempre percibimos, y nos obligamos de igual manera a incorporar junto a estas 
líneas mapas -al menos uno del Mediterráneo y otro de España- a fin de enmarcar los contenidos en el espacio geográfico y que el alumno nunca lo perdiera de vista. Otros eleméntenos que decidimos incorporar fueron los cuadros sinópticos, y los esquemas conceptuales, que permitieran al alumno entender de manera clara y sistemática parte de los contenidos. Además, se potenció el uso de imágenes de apoyo que aumentaran las posibilidades educativas de los materiales, redundaran en su originalidad e innovación y mejoraran la aceptación y utilidad de los contenidos por parte de los alumnos (ver imagen 8).

Uno de los apartados en el que más énfasis se puso fue en la elaboración de los materiales didácticos para el desarrollo de las prácticas en la asignatura de Fundamentos de Historia. La necesidad de explicar de manera clara cuál era el objetivo de los trabajos que los alumnos desarrollarían a lo largo de la asignatura y el enfoque genérico que permitiera extrapolar las actividades a otras titulaciones nos llevo a diseñar nuevos equipos de trabajo entre los miembros del equipo del proyecto de 2017 con el propósito de analizar las Unidades didácticas (UDs) recopiladas desde 2012 y generar modelos estandarizados en los que se incorporaran los elementos mínimos de cada UD, la bibliografía imprescindible, así como ejemplo de actividades para su desarrollo (ver imagen 7).

\section{RESULTADOS DE LA APLICACIÓN}

Tras la edición de la herramienta tuvimos ciertas dificultades a la hora de presentar los resultados debido a que algunos de los objetivos venían aplicándose durante el periodo de elaboración del mismo, concretamente los objetivos del 4 al 6 , centrados en la mejora del aprendizaje por medio de recursos que afectaran a la evaluación. Desde 2012 a 2017 se fue desarrollando el sistema de prácticas de unidades didácticas que presentaba un $30 \%$ de la nota de la parte de la asignatura propia al Dpto. de H. a Antigua y un $30 \%$ de la nota en la Escuela Universitaria de Osuna en la que la asignatura es impartida por un solo profesor. Sin embargo, era necesario algún indicador que nos orientase sobre la validez y uso de los nuevos materiales.

Si bien los profesores hemos detectado que el sistema de prácticas ha mejorado la participación en las clases y hay un consenso en que gracias a ellas el alumno profundiza en ciertos aspectos de la materia consiguiendo una mayor implicación, es difícil cuantificar el éxito del nuevo manual, ya que la introducción metodológica ha ido realizándose de manera previa.

Para esta evaluación el mismo año de publicación realizamos un análisis de los resultados centrándonos en la evolución académica de varios grupos de estudiantes. Los criterios que seguimos para seleccionar los mismos fueron la continuidad del profesorado, una cuestión complicada al estar sujeta a la elaboración de 
los planes de organización de docentes, y la introducción paulatina de los nuevos materiales. Además, generamos un grupo de control, en el que el nuevo manual aún no había sido incorporado, que sirviera de referencia para apreciar los posibles progresos.

De esta manera, en 2017, presentamos las estadísticas académicas de la primera convocatoria de exámenes de los últimos tres años en los grupos en que el profesor Álvarez-Ossorio impartió clase y el propio de 2017 en el que introdujo paulatinamente los materiales según se iban generando (Sánchez, Álvarez-Ossorio, Alarcón y Lozano, 2018, pp. 176-179). La elección de estos grupos se debió a que el profesor Álvarez-Ossorio ha impartido la asignatura desde su implantación en el grado hasta la fecha actual y representa la continuidad y evolución en la metodología de la misma. Los resultados de sus grupos se compararon con las estadísticas de los grupos en los que ha sido docente el profesor Sánchez Domínguez, profesor de la asignatura en la Escuela Universitaria de Osuna desde 2014. En sus grupos se prefirió no cambiar la metodología docente con respecto al manual hasta que el proceso de edición, publicación y difusión no estuviera terminado, hecho que no ocurrió hasta el curso 2017-2018, permitiéndonos poder usar sus estadísticas como grupo de control en el curso 2016-17.

Así podemos observar como en los grupos del profesor Álvarez-Ossorio se produjo una evolución positiva identificando como primer resultado un claro descenso en el abandono de la asignatura, reduciéndose el número de no presentados. En este punto hay que aclarar una situación que modifica los resultados del grupo de control al ser el curso 2014-15 el primer año con un nuevo profesor, lo que causó un efecto llamada de alumnos repetidores reduciendo el número de no presentados de manera considerable con respecto a los cursos siguientes (ver tablas 3 y 4$)$.

En la relación de estudiantes que no llegaron al mínimo en cuanto a los objetivos podemos observar un leve descenso más pronunciado en el curso 2015-16 en el que se comienza a introducir las primeras versiones del manual (hemos de aclarar que en el curso 2016-17 hay un aumento de alumnos que se presentan afectando al número de suspensos y demás notas aumentando levemente el número). Esta variación no se aprecia en el grupo de control en el que se mantienen los materiales tradicionales y los apuntes de clase en vez del nuevo manual (ver tablas 3 y 4$)$.

En lo referente a las demás calificaciones se constató en ambos grupos una mejora constante en los resultados, debida a la familiarización con los grupos, contenidos y metodología aunque el grupo que incorpora los nuevos materiales (el manual 2.0 y sus versiones de prueba) sufre un claro descenso en el número de aprobados debido al trasvase y mejoría en calificaciones de notable y sobresaliente, un fenómeno que no se aprecia de manera tan marcada en el grupo de control (ver tablas 3 y 4 ). 


\begin{tabular}{|c|c|c|c|c|c|c|}
\hline \multirow{2}{*}{ Notas } & \multicolumn{2}{|c|}{ Alumnado 2014/2015 } & \multicolumn{2}{c|}{ Alumnado 2015/2016 } & \multicolumn{2}{c|}{ Alumnado 2016/2017 } \\
\cline { 2 - 7 } & Grupo & Muestra & Grupo & Muestra & Grupo & Muestra \\
\hline No presentados & 45 & 6 & 47 & 18 & 22 & 13 \\
\hline Suspenso & 32 & 10 & 29 & 11 & 29 & 15 \\
\hline Aprobado & 22 & 27 & 16 & 13 & 12 & 17 \\
\hline Notable & 32 & 7 & 76 & 14 & 51 & 18 \\
\hline Sobresaliente & 2 & 1 & 19 & 1 & 14 & 0 \\
\hline Matrícula de Honor & 6 & 2 & 4 & 3 & 6 & 1 \\
\hline
\end{tabular}

Tabla 3. Evolución de las evaluaciones de los alumnos 2014-2017.

\begin{tabular}{|c|c|c|c|c|c|c|}
\hline \multirow{2}{*}{ Notas } & \multicolumn{2}{|c|}{$\begin{array}{c}\text { Alumnado (\%) } \\
\mathbf{2 0 1 4 / 2 0 1 5}\end{array}$} & \multicolumn{2}{c|}{$\begin{array}{c}\text { Alumnado (\%) } \\
\mathbf{2 0 1 5 / 2 0 1 6}\end{array}$} & \multicolumn{2}{c|}{$\begin{array}{c}\text { Alumnado (\%) } \\
\mathbf{2 0 1 6 / 2 0 1 7}\end{array}$} \\
\cline { 2 - 7 } & Grupo & Muestra & Grupo & Muestra & Grupo & Muestra \\
\hline No presentados & 32,37 & 11,3 & 24,60 & 30 & 15,27 & 20,30 \\
\hline Suspenso & 23,02 & 18,90 & 15,18 & 18,33 & 20,13 & 23,40 \\
\hline Aprobado & 22 & 50,90 & 8,37 & 21,66 & 8,33 & 26,60 \\
\hline Notable & 15,82 & 13,2 & 39,78 & 23,33 & 35,41 & 28,10 \\
\hline Sobresaliente & 1,43 & 1,9 & 9,94 & 1,66 & 9,92 & 0 \\
\hline Matrícula de Honor & 4,31 & 3,8 & 2,09 & 5 & 4,16 & 1,6 \\
\hline
\end{tabular}

Tabla 4. Evolución de las evaluaciones de los alumnos de manera porcentual 2014-2017.

\section{Evolución de los grupos en ralación con}

\section{la incorporación de nuevos materiales}

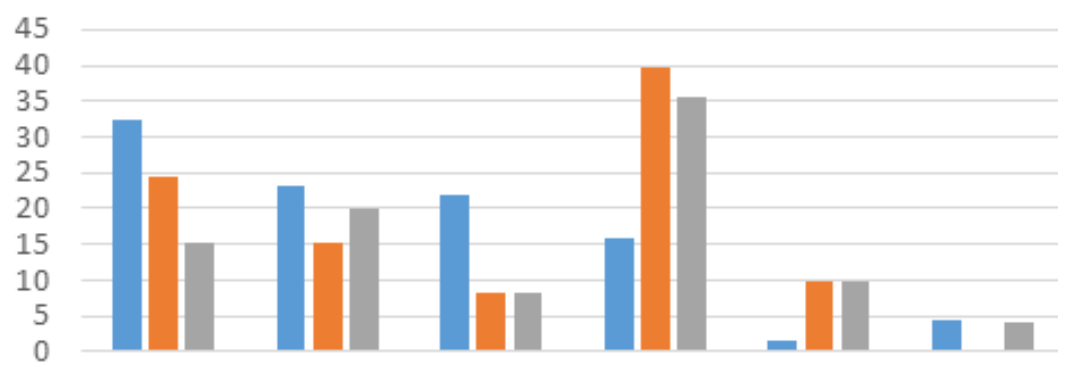




\section{Evolución del grupo control}

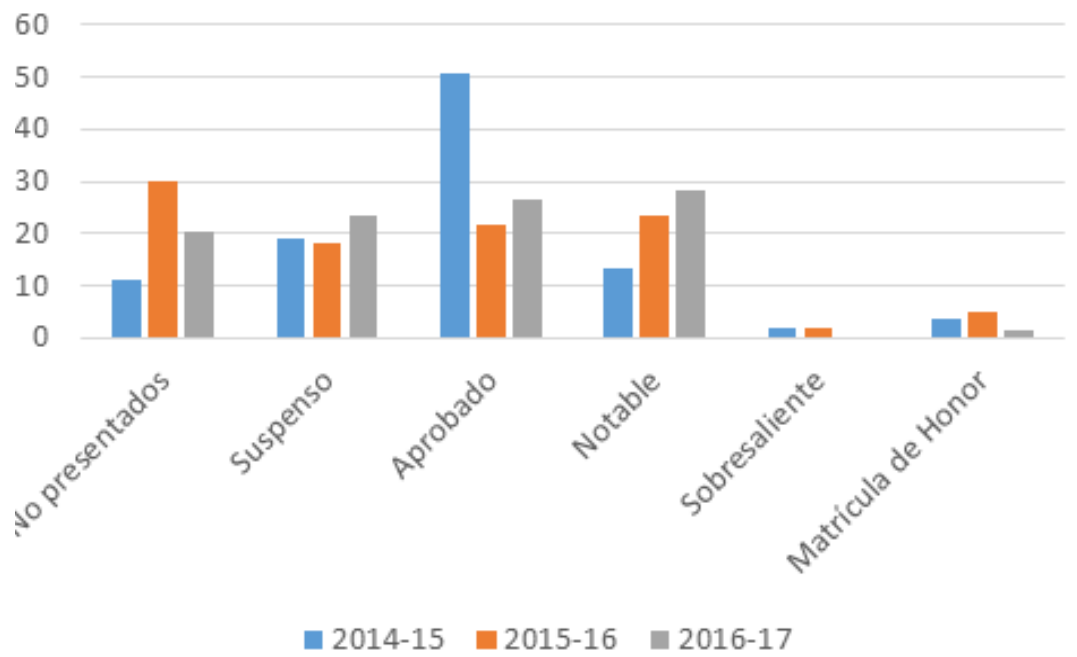

Otro índice relativo de éxito es el número de descargas del manual, el cual, al estar alojado en el repositorio de la biblioteca de la universidad de Sevilla, puede seguirse sin dificultad identificando el número de descargas totales desde 2017, de 1584 , y un total de 2723 consultas, pudiéndose identificar además un desglose por mes en el que vemos cómo las consultas se centran en los meses asociados al inicio de la asignatura entre enero y febrero (véase ilustración 1). Ciertamente hemos de recalcar el alcance relativo de estas estadísticas, que no reflejan el total debido a varias circunstancias. La primera es que en el centro adscrito donde desde el curso pasado se incorporó el manual no vuelca sus datos de consulta de los $C D$ a través de los cuales acceden parte de su alumnado; además, el poder descargarlo en PDF supone que es almacenable y por tanto puede transferirse entre compañeros de un dispositivo a otro por medio de memorias USB u otros medios sin dejar un rastro de este proceso y evitando consumir datos en dispositivos portátiles o tiempo de conexión.

Por último, y como veremos más adelante, hemos continuado trabajando desde el equipo docente en diferentes proyectos de innovación, siendo uno en 2017/18 cuyo resultado ha sido la creación del blog "Fundamentos de Historia» (<https://fhantiguaymedieval.blogspot.com/>) desde el cual se puede consultar el manual sin necesidad de ser descargado en una vista por capítulos, por lo que debemos tener en cuenta este dato a la hora de formarnos una idea del impacto del recurso. 


\section{CONCLUSIONES PRELIMINARES, CAMINO A UN LIBRO 3.0}

Tras la exposición de estos datos podemos afirmar que la introducción del manual y el cambio de metodología docente han supuesto una mejora en los resultados académicos, en el nivel de participación del alumno en las clases, así como en el dinamismo con el que transcurren las mismas. El alcance del manual todavía se circunscribe al ámbito local, aunque se aprecian diferentes descargas y consultas desde otras ciudades, comunidades y países, hecho que nos sorprende, ya que no se ha realizado una difusión del mismo (véase tabla 5).

\begin{tabular}{cccccc} 
Países con más consultas & Total & & Ciudades con más consultas & Total \\
\cline { 1 - 2 } \cline { 5 - 5 } España & 1303 & & Sevilla & 261 \\
Estados Unidos & 56 & & Madrid & 103 \\
República Dominicana & 21 & & Málaga & 39 \\
México & 21 & & Dos Hermanas & 38 \\
Argentina & 19 & & Barcelona & 32 \\
Ecuador & 18 & & Los Palacios y Villafranca & 25 \\
Colombia & 15 & & La Puebla De Cazalla & 23 \\
Reino Unido & 12 & & El Viso Del Alcor & 18 \\
Irlanda & 12 & & Zaragoza & 17 \\
Alemania & 10 & & Valencia & 16 \\
\cline { 5 - 6 } & & & &
\end{tabular}

Tabla 5. Datos extraídos del servicio IdUS a fecha de 20/02/2019.

Pese a todo tenemos que decir que los resultados expuestos en este punto distan aún mucho de ser concluyentes debido al poco lapso de tiempo estudiado y resultará difícil profundizar en los mismos, ya que aunque pretendemos mantener la continuidad del análisis apoyándonos en los recursos estadísticos de la Universidad de Sevilla a partir de la Secretaría Virtual y al sistema de encuestas de evaluación del profesorado de dicha universidad, así como de los datos facilitados por IdUs, deberemos introducir nuevas variables, pues el proyecto sigue en expansión.

Las convocatorias de ayudas de los planes de innovación docentes de la Universidad de Sevilla son un recurso a la vez que un motor de cambio, ya que en los últimos dos años, tras la finalización del proyecto de edición del libro, hemos conseguido la obtención de dos proyectos más, los cuales se engarzan directamente con la ampliación de este manual digital en busca de convertirlo en material multimedia.

En la convocatoria de 2017/18 con la ayuda del técnico Rodolfo Domínguez Petit, hemos incorporado materiales lúdicos a nuestra metodología docente por medio del diseño de diferentes secuencias de preguntas respuestas por medio 
de la aplicación Kahoot, así mismo se ha diseñado el blog antes referido, así como el canal de YouTube "Fundamentos de Historia» en (<https://www.youtube.com/channel/UC1c4kHIKTb-PMbvQYezellw>, véase ilustración 3), en el cual hemos alojado diversos videos que se han incrustado en el programa Kahoot para enriquecerlo, dotando a las preguntas de un entorno visual, una descripción de las mismas y una explicación de las respuestas relacionadas con los contenidos del manual. Aún hay cuestiones que pulir, como el excesivo peso del archivo, así como su formato, no obstante, el siguiente paso en este camino es habilitar un nuevo archivo, con enlaces e inclusión de estos nuevos materiales, así como la incorporación de otros nuevos a modo de elementos multimedia que enriquezcan los contenidos y que permitan la interacción entre el alumnado y el manual.

Este proyecto es solo parte de una propuesta de solución pedagógica global con la que adaptarse a la nueva realidad, que poco a poco altera la realidad de lo que sucede en el aula, ya también en la educación superior universitaria. Nuestros alumnados han cambiado y es hora de que evolucionemos junto a ellos, a fin de darle un futuro, no solo a lo que desde nuestra parte corresponda a su formación, sino también a nuestra realidad didáctica, que parece estar en peligro de desdibujarse o incluso de desaparecer. Debemos generar alternativas para la enseñanza a nivel universitario y la divulgación de la Historia. Es nuestro deber como historiadores y educadores encontrar un equilibrio entre la transmisión y estudio de la historia y las necesidades de nuestro alumnado. Así, pretendemos con esta aportación promover un cambio que en nuestro caso no queda solo en una modernización de los materiales, sino que en realidad consiste en acometer una búsqueda por adaptar en nuestras clases las nuevas metodologías como la gamificación y los juegos de roles, estrategias que hemos comenzado a incorporar y esperamos poder seguir evaluando con el fin de mejorar nuestra docencia.

\begin{tabular}{|c|c|c|c|c|c|c|}
\hline \multirow{2}{*}{ Notas } & \multicolumn{2}{|c|}{ Alumnos 2014/2015 } & \multicolumn{2}{c|}{ Alumnos 2015/2016 } & \multicolumn{2}{c|}{ Alumnos 2016/2017 } \\
\cline { 2 - 7 } & Grupo & Muestra & Grupo & Muestra & Grupo & Muestra \\
\hline No presentados & 45 & 6 & 47 & 18 & 22 & 13 \\
\hline Suspenso & 32 & 10 & 29 & 11 & 29 & 15 \\
\hline Aprobado & 22 & 27 & 16 & 13 & 12 & 17 \\
\hline Notable & 32 & 7 & 76 & 14 & 51 & 18 \\
\hline Sobresaliente & 2 & 1 & 19 & 1 & 14 & 0 \\
\hline $\begin{array}{c}\text { Matrícula de } \\
\text { Honor }\end{array}$ & 6 & 2 & 4 & 3 & 6 & 1 \\
\hline
\end{tabular}

Tabla 6. Comparativa de resultados académicos entre grupos y muestra. Cursos 2014 a 2017. 


\section{ANEXO I - IMÁGENES}

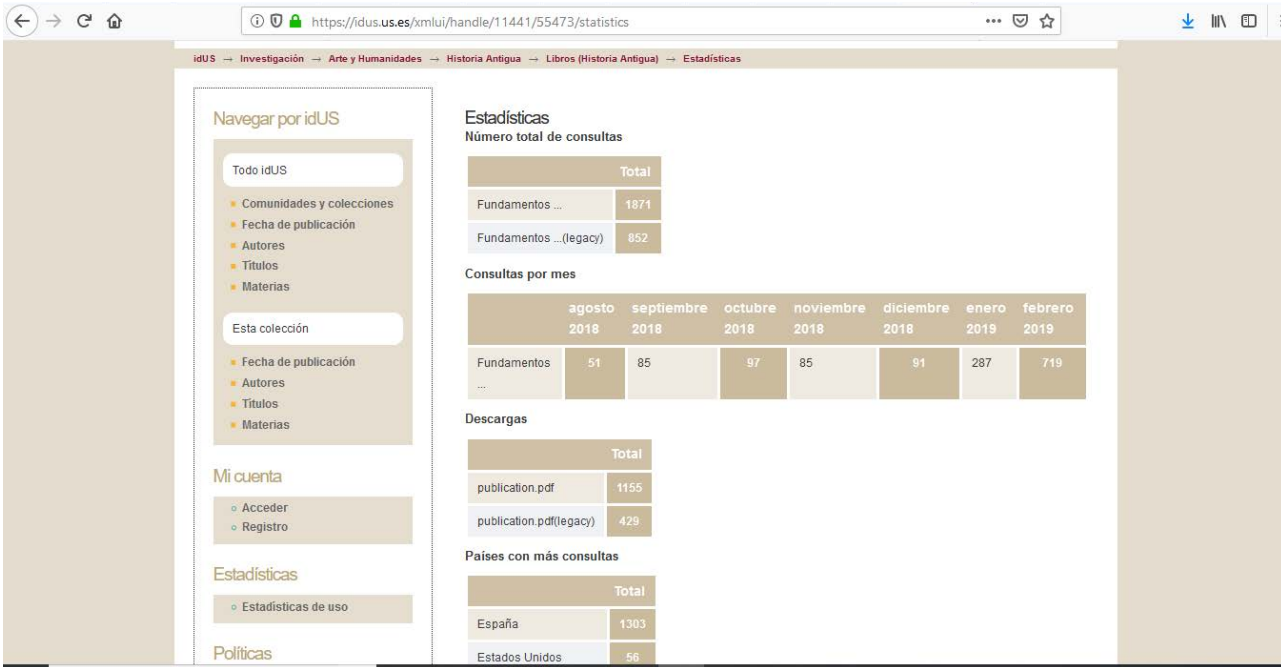

Ilustración 1. Captura de pantalla con estadísticas alojadas en IdUS sobre el libro Fundamentos de Historia: Historia Antigua y Medieval de España. <https://idus.us.es/xmlui/handle/11441/55473/statistics>. Consulta 20/02/2019.

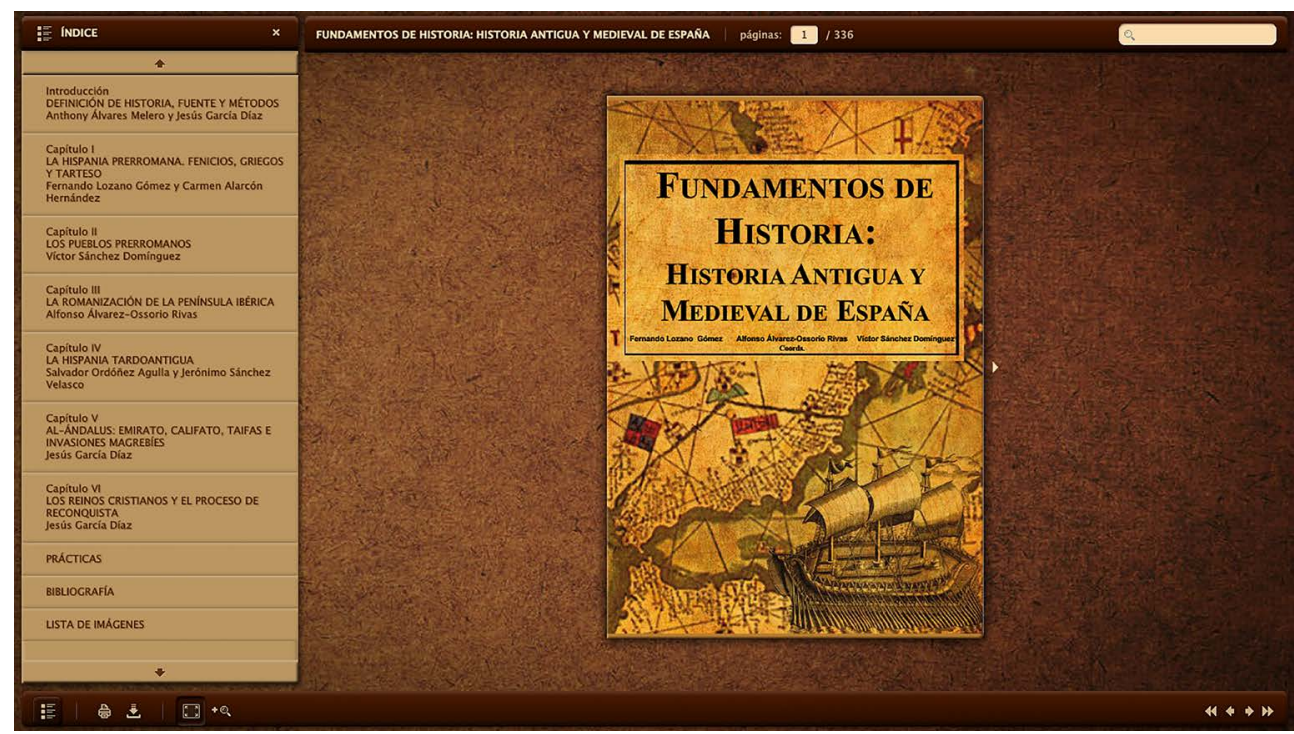

Ilustración 2. Captura de pantalla de la versión digital del manual Fundamentos de Histora: Historia Antigua y Medieval de España (Lozano Gómez, Álvarez-Osorio Rivas y Sánchez Domínguez, 2017). 


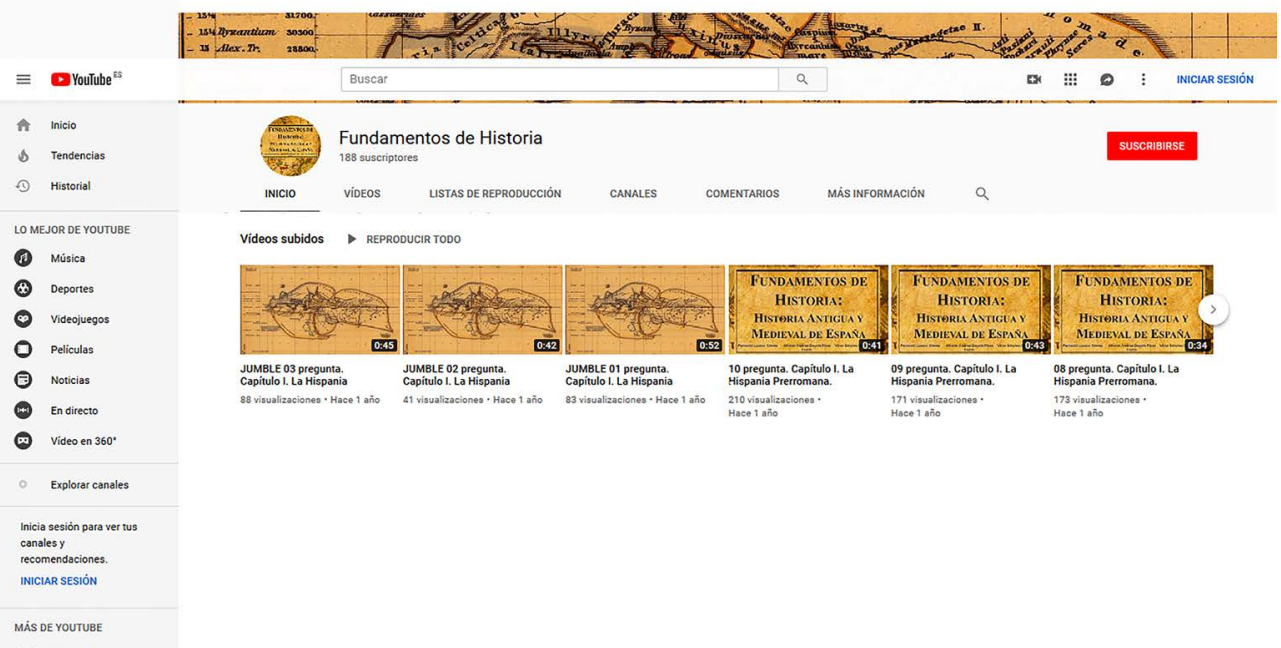

Ilustración 3. Canal de YouTube «Fundamentos de Historia». Consulta 21/02/2019.

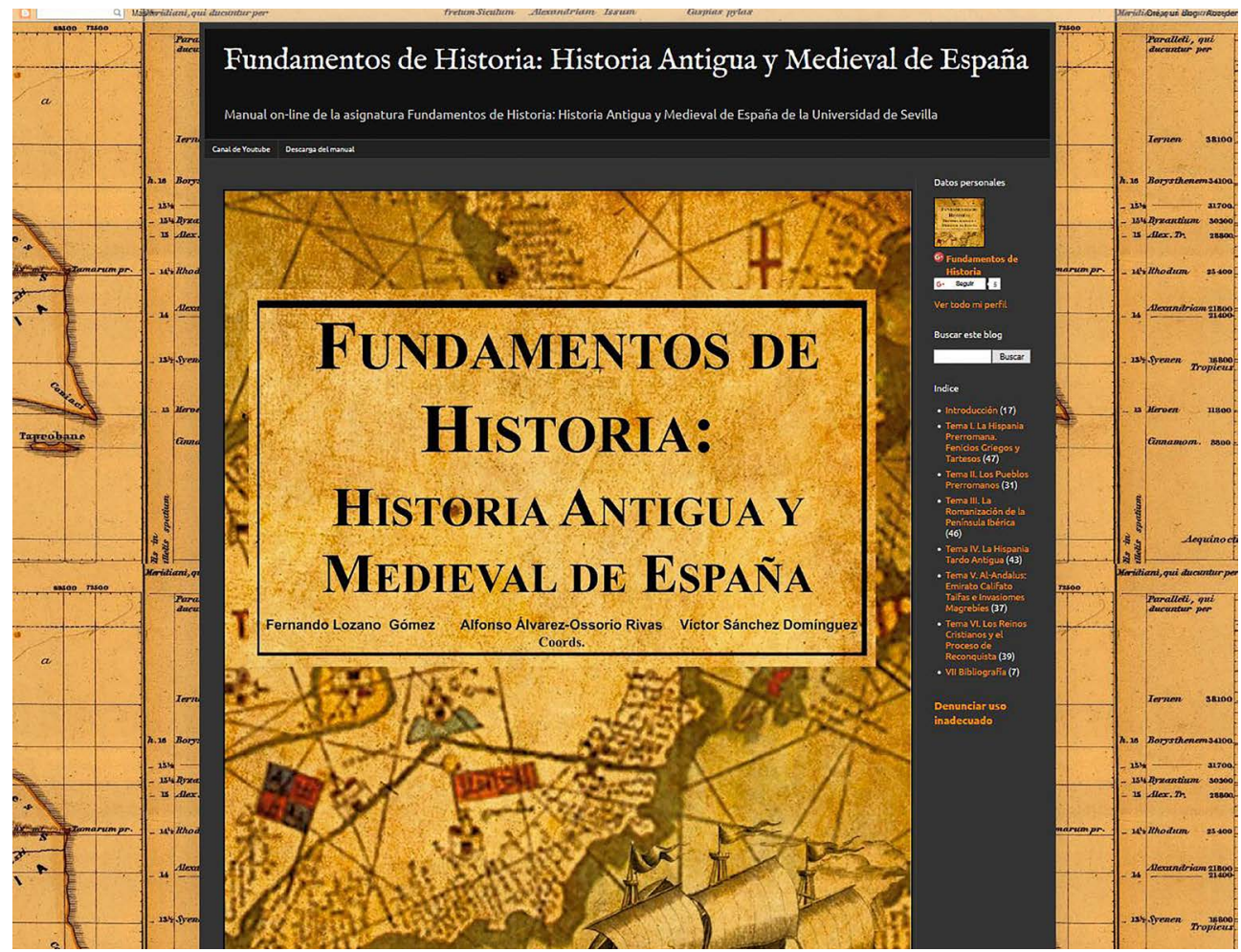

Ilustración 4. Captura de pantalla «Blog Fundamentos de Historia». <https://fhantiguaymedieval.blogspot.com/>. Consulta 19/02/2019. 


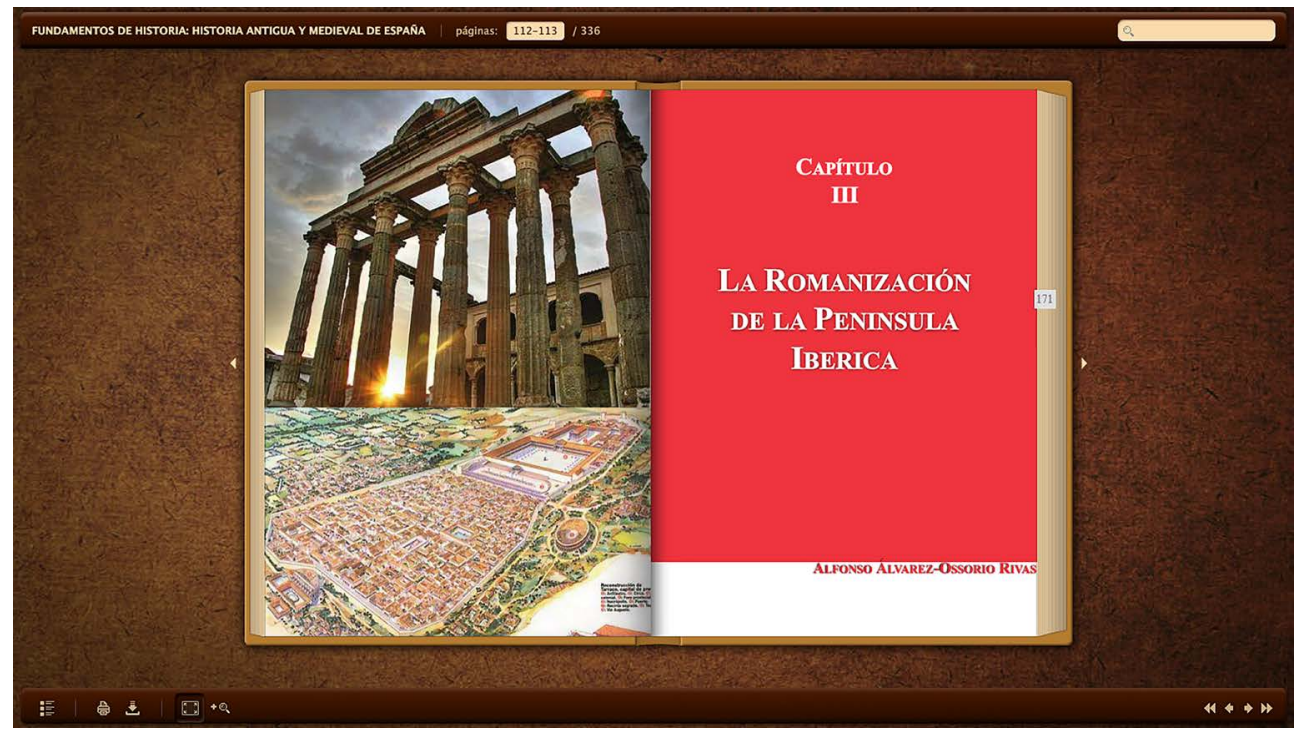

Ilustración 5. Captura de pantalla de comienzo de capítulo con imágenes emblemáticas.

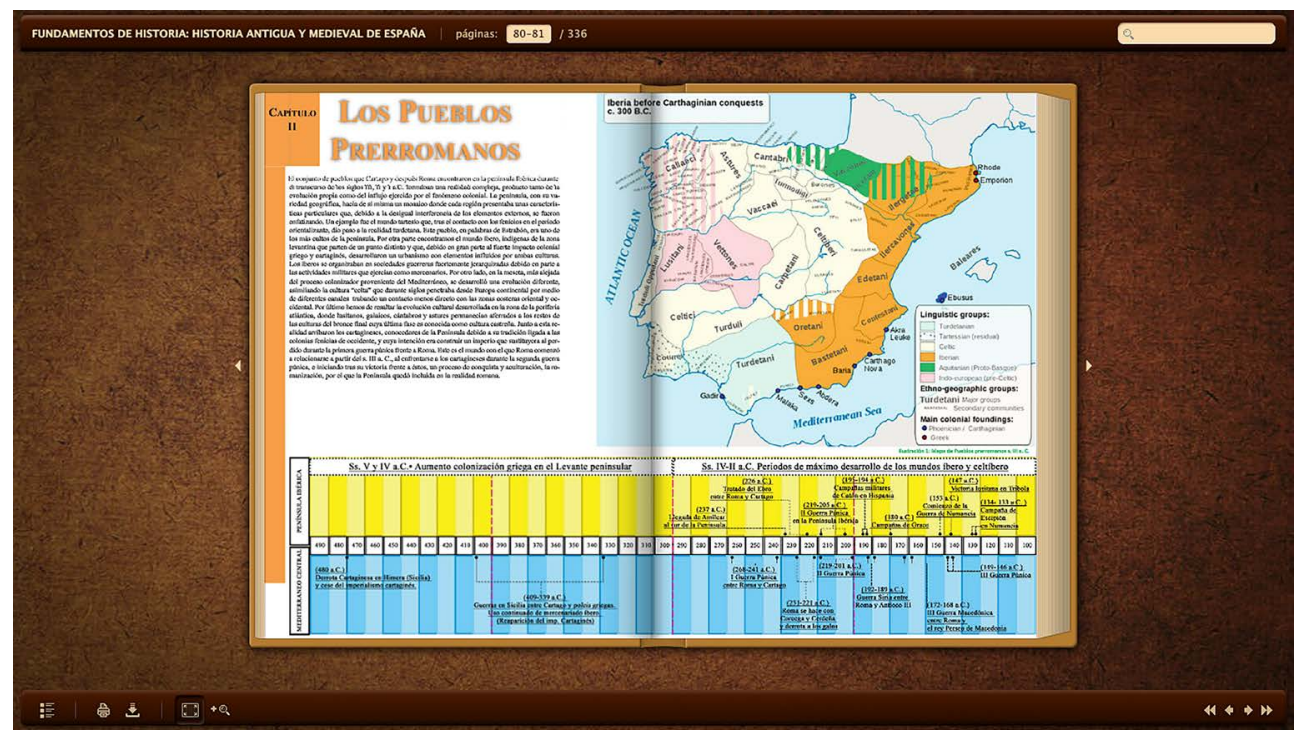

Ilustración 6. Captura de pantalla con ejemplo de introducción de capítulo con mapas y eje cronológico. 


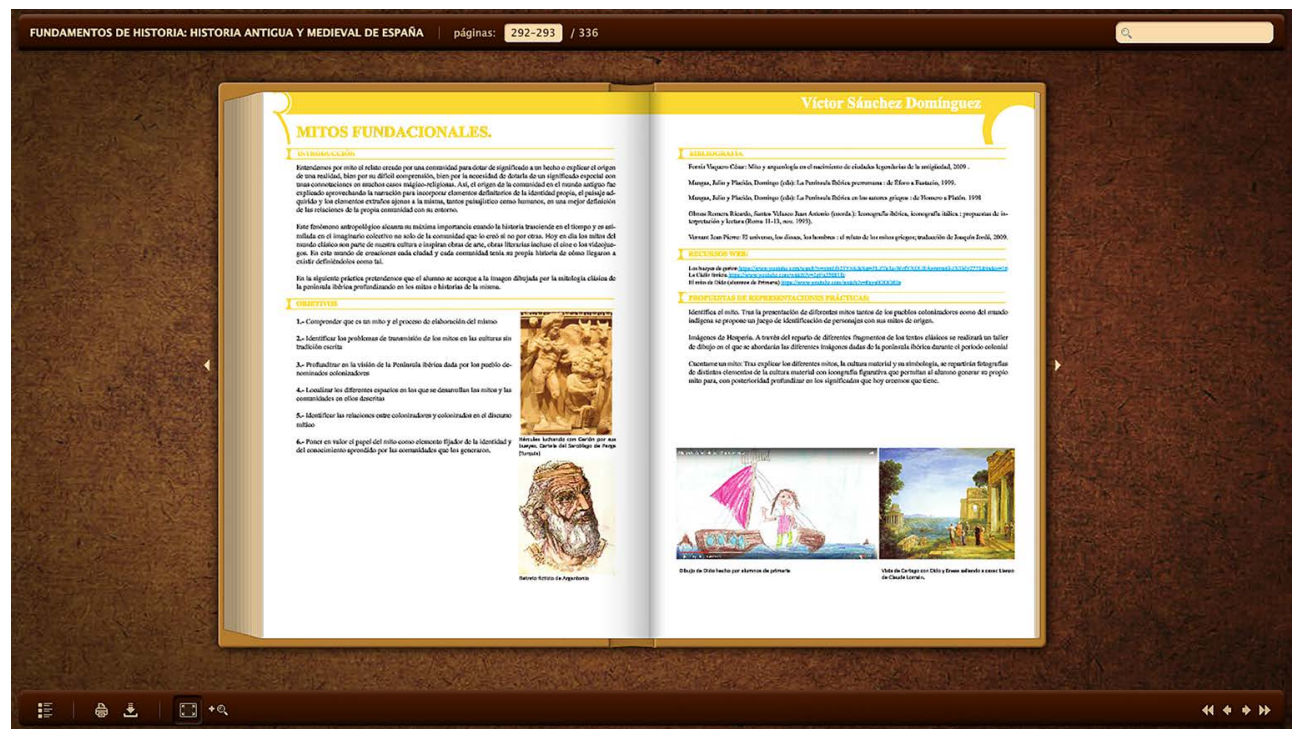

Ilustración 7. Captura de pantalla con ejemplo de materiales para elaboración de prácticas de programación de unidades didácticas.

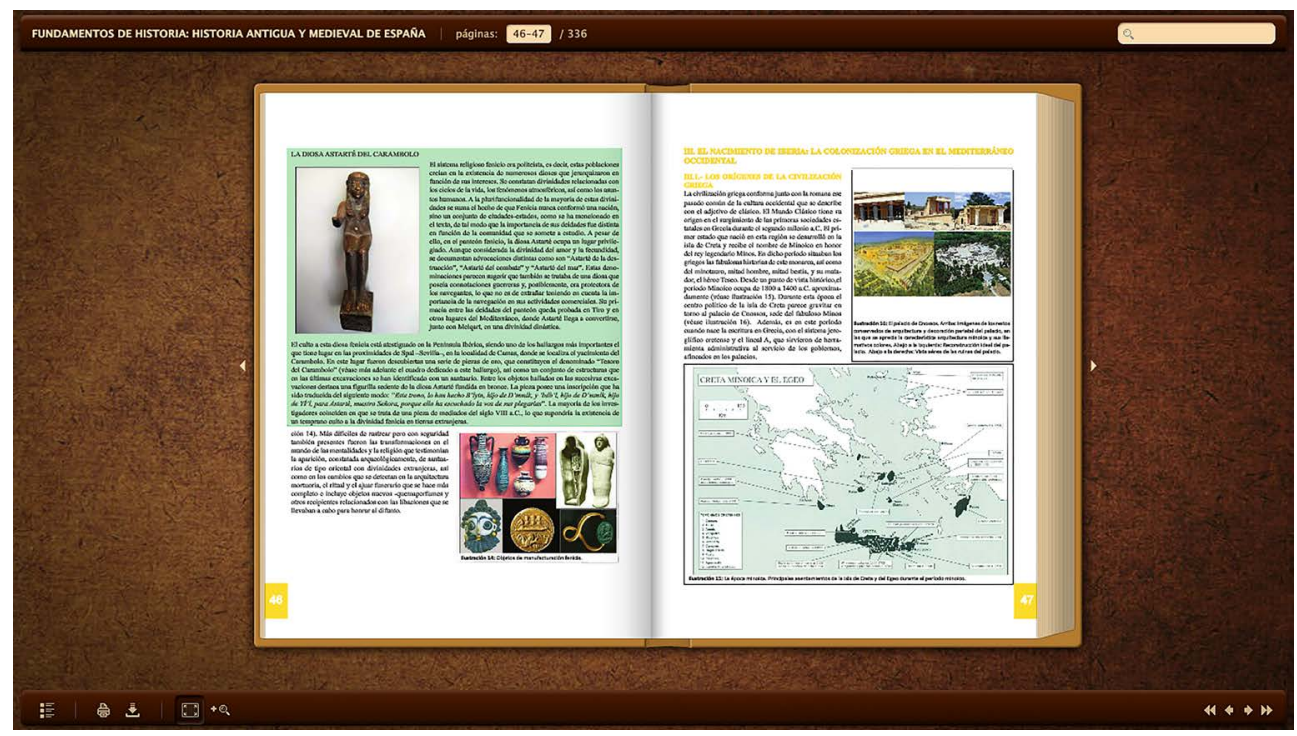

Ilustración 8. Captura de pantalla con ejemplo de interior de capítulo con imágenes, mapas, cuadros textuales y otros elementos. 


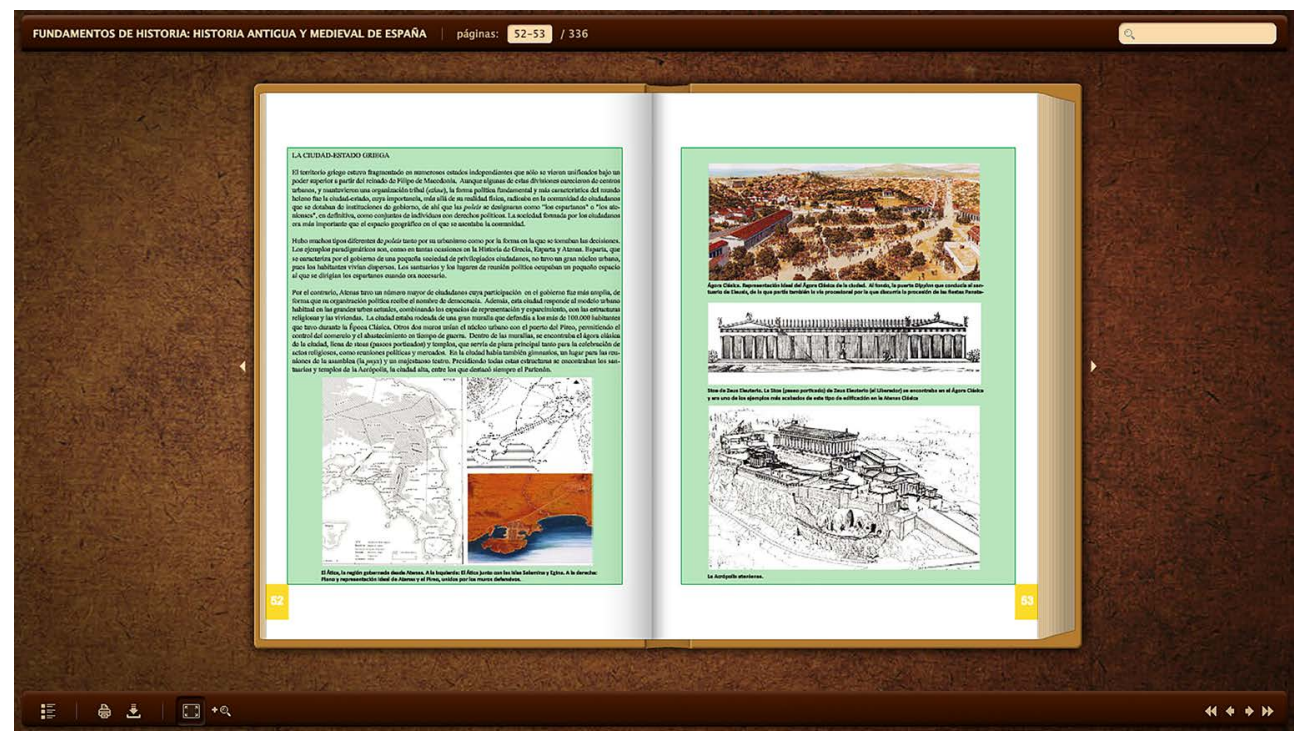

Ilustración 9. Captura de pantalla con ejemplo de dossier temático. 


\section{ANEXO II - ENCUESTA PROYECTO}

1.- Los principales colonizadores del sur de la Península Ibérica antes de nuestra era fueron:
A) Los fenicios. $X$
B) Los griegos.
C) Los etruscos.

2.- Las principales motivaciones de la colonización fenicia fueron:
A) El comercio y la obtención de materias primas. $X$
B) Constituir un imperio en esta región.
C) La conversión religiosa de la población autóctona.

3.- La principal civilización indígena del sur de la Península Ibérica durante las colonizaciones fue:
A) Tartessos. $X$
B) Numancia.
C) Vetones.

4.- Los fenicios fundaron, entre otras, una importante ciudad en el norte de África que, a la larga, también estaría presente en la Península Ibérica. Se trata de:
A) Cirene.
B) Alejandría.
C) Cartago. $X$

5.- El contacto de las élites indígenas con los colonizadores provocó:
A) Su desaparición.
B) Su aculturación y sofisticación. $X$
C) Una profunda decadencia cultural.

6.- Numancia es una ciudad:
A) Ibérica.
B) Celta.
C) Celtíbera. $X$

7.- ¿Quiénes combatieron en la Segunda Guerra Púnica?
A) Romanos y cartagineses. $X$
B) Romanos y griegos.
C) Cartagineses y fenicios. 
8.- Viriato fue un caudillo:
A) Visigodo.
B) Ibérico.
C) Lusitano. $X$

9.- ¿Cuál es el nombre de la primera fundación romana en Hispania?
A) Hispalis.
B) Itálica. X
C) Tarraco.

10.- ¿Cuál era la capital de la Bética?
A) Corduba. $X$
B) Hispalis.
C) Emerita Augusta.

11.- El emperador romano Augusto dividió la Península Ibérica en tres provincias:
A) Gallaecia, Lusitania y Bética.
B) Hispania Citerior, Tingitania y Bética.
C) Lusitania, Bética y Tarraconensis. $X$

12.- ¿Qué diferenciaba a las provincias senatoriales de las imperiales?
A) La presencia de legiones acantonadas en el territorio. $X$
B) La existencia de minas de oro.
C) La existencia de colonias romanas.

13.- ¿Cuáles de los siguientes productos y materias primas se exportaron abundantemente de Hispania durante el Imperio romano?
A) Aceite de oliva y salazones. $X$
B) Naranjas y estaño.
C) Trigo y vino.

14.- ¿Qué dos emperadores del siglo II d.C. pertenecieron a familias de Itálica?
A) Agripa y Augusto.
B) Adriano y Trajano. $X$
C) Marco Aurelio y Trajano.

15.- ¿Qué tres escritores romanos pertenecieron a familias de Hispania?
A) Tito Livio, Horacio y Virgilio.
B) Séneca, Tito Livio y Lucano.
C) Lucano, Séneca y Marcial. X 
16.- ¿Cuál de los siguientes pueblos bárbaros no se asentó en la península ibérica?
A) Los suevos.
B) Los visigodos.
C) Los sajones. $X$

17.- ¿Cuál de los siguientes emperadores tuvo orígenes hispanos?
A) Teodosio. $X$
B) Constantino.
C) Galerio.

18.- ¿Cuál de estas religiones profesaban los visigodos cuando llegaron a la península Ibérica?
A) El islam.
B) El cristianismo arriano. $X$
C) El judaísmo.

19.- ¿Cuál de las siguientes potencias no cohabitó con el mundo visigodo en la península ibérica?
A) El imperio bizantino.
B) El reino suevo.
C) El reino franco. $X$

20.- ¿Con qué batalla comenzó la conquista musulmana de la Península Ibérica?
A) Covadonga.
B) Guadalete. X
C) Navas de Tolosa.

21.- La capital administrativa del Califato andalusí estaba en:
A) Toledo.
B) Sevilla.
C) Córdoba. $X$

22.- La dinastía que gobernó Granada hasta su toma en 1491 se llamaba:
A) Omeya.
B) Abásida.
C) Nazarí. X

23.- La Giralda de Sevilla pertenece al estilo:
A) Almohade. $X$
B) Andalusí.
C) Magrebí. 
24.- Las divisiones administrativas del territorio de Al-Andalus se denominan:
A) Provincias.
B) Emiratos.
C) Coras. $\mathrm{X}$

25.- El centro de mercado en una ciudad andalusí se denomina:
A) Foro.
B) Plaza.
C) Zoco. X

26.- Cómo se llamaban los territorios controlados por Carlomagno en la Península Ibérica?
A) Marca Franca.
B) Marca Hispánica. X
C) Condados Catalanes.

27.- ¿Cuál fue el primero de los reinos cristianos peninsulares?
A) Asturias. $X$
B) León.
C) Castilla.

28.- ¿Cómo se denomina a los musulmanes que permanecieron viviendo en los territorios conquistados por los cristianos?
A) Almogáraves.
B) Almohades.
C) Mudéjares. X

29.- ¿Qué nombre recibía el gremio de los pastores y ganaderos castellanos creado por Alfonso X?
A) Honrado Concejo de la Mesta. $X$
B) Casa de Ganaderos de Zaragoza.
C) Cofradía de Ganaderos de Castilla.

30.- ¿Cuál fue el motor económico de Castilla tras la gran crisis del s. XIV?
A) El cultivo del olivar y el comercio de aceite.
B) La minería y comercio del hierro.
C) La producción y comercio de lana. $X$ 


\section{REFERENCIAS BIBLIOGRÁFICAS}

Alvar Ezquerra, J. (dir.). (2007). Entre fenicios y visigodos: la Historia Antigua de la Península Ibérica. España: La Esfera de los Libros.

Álvarez, Melero, A., Álvarez-Ossorio, Rivas, A., Cidoncha, Redondo, F., y Sánchez Domínguez, V. (2017). El uso del Kahoot y del Jumble como herramienta de trabajo para la enseñanza para la Historia Antigua y Medieval de España. En M. Rodríguez Lopez y R. Anguita Martínez (coords.), Innovaciones en el aprendizaje con tecnologías digitales (pp. 97-108). Camas: Egregius.

Barceló, P. y Ferrer, J. J. (2007). Historia de la Hispania romana. Madrid: Alianza

Buzón García O. (ed.). (2018). Innovación y tendencias educativas: un camino hacia nuevas formas de aprendizaje. Camas: Egregius.

Caballero Oliver, J. D. (2000). Didáctica de las Ciencias Sociales para profesores de Educación Secundaria. Sevilla: MAD.

Cooper, H. (2002). Didáctica de la historia en la educación infantil y primaria. Madrid: Morata.

García de Cortázar, F. y González Vesga, J. M. (2009). Breve Historia de España. Madrid: Alianza.

Hernández Cardona, F. X. (2002). Didáctica de las Ciencias Sociales Geografía e Historia. Barcelona: Graò.

Lozano Gómez, F. (2013). Roma domina el mundo. Collection Historia. National Geographic. Barcelona: The National Geographic Society.

Lozano Gómez, F., Álvarez-Ossorio Rivas, A. y Sánchez Domínguez, V. (2017). Fundamentos de Historia. Historia Antigua y Medieval de España. Sevilla: Servicio de Audiovisuales Universidad de Sevilla.

López Facal, R. (2014). La LOMCE y la competencia histórica. Ayer, 94(2), pp. 273285.

Mitre, E. (1979). La España medieval: sociedades, estados, culturas. Madrid: Istmo.

Porlan, R. (2017). Enseñanza universitaria. Cómo mejorarla. Madrid: Morata. 
Rivas Rivas, F. A. y Álvarez-Ossorio Rivas, A. (2006). Una Ventana al Pasado. Historia de Bollullos de la Mitación. Sevilla: Padilla Libros Editores y Libreros.

Rodríguez López, M. y Anguita Martínez, R. (coords.). (2018). Innovaciones en el aprendizaje con tecnologías digitales. Camas: Egregius.

Salinas de Frías, M. (2006). Los pueblos prerromanos de la península ibérica. Madrid: Akal.

Sánchez Domínguez, V., Álvarez-Ossorio Rivas, A., Alarcón Hernández, C. y Lozano Gómez F. (2018). Innovación didáctica de la Historia: del manual al libro 2.0. Nuevos modelos de educación para nuevas necesidades educativas. En $\mathrm{O}$. Buzón García (ed.), Innovación y tendencias educativas: un camino hacia nuevas formas de aprendizaje (pp. 161-185). Camas: Egregius.

Suárez Fernández, L. (1986). Historia de España Antigua y Media. Madrid: Rialp.

Trepat. C. A. y Comes, P. (1998). El tiempo y el espacio en la didáctica de las Ciencias Sociales. Barcelona: Graò. 